Article

\title{
Reproducible Design for the Optical Screening and Sensing of Hg(II) Ions
}

\author{
Emad A. Elshehy ${ }^{1, \dagger}$, Sherif A. EL-Safty ${ }^{1,2, *}$ and Mohamed A. Shenashen ${ }^{1, \ddagger}$ \\ 1 National Institute for Materials Science (NIMS), 1-2-1 Sengen, Tsukuba-shi, \\ Ibaraki-ken 305-0047, Japan; E-Mails: elshehy.emad@nims.go.jp (E.A.E.); \\ shenashen.mohameda@nims.go.jp (M.A.S.)
}

2 Graduate School for Advanced Science and Engineering, Waseda University, 3-4-1 Okubo, Shinjuku-ku, Tokyo 169-8555, Japan

$\dagger$ Permanent address: Nuclear Materials Authority, El Maadi, Cairo, Egypt.

$\ddagger$ Permanent address: Egyptian Petroleum Research Institute (EPRI), Nasr City, Cairo, Egypt.

* Author to whom correspondence should be addressed; E-Mail: sherif.elsafty@nims.go.jp or sherif@aoni.waseda.jp; Tel.: +81-298-592-135; Fax: +81-298-592-025.

External Editor: Igor Medintz

Received: 1 April 2014; in revised form: 22 September 2014 / Accepted: 25 September 2014 / Published: 24 October 2014

\begin{abstract}
We fabricated silica nanotubes with hexagonally ordered mesopores $(6 \mathrm{~nm})$ inside a membrane disc with a uniform channel neck size of $200 \mathrm{~nm}$ and a longitudinal thickness of $60 \mu \mathrm{m}$ to design an optical sensor membrane (OSM) for the screening and sensing of extremely toxic $\mathrm{Hg}$ (II) ions. The optical detection and quantitative recognition of $\mathrm{Hg}$ (II) ions in water were conducted even at trace concentrations without the need for sophisticated instruments. The OSM design was based on the physical interaction of a responsive organic probe with silica pore surfaces followed by strong and selective binding $\mathrm{Hg}(\mathrm{II})$-probe interactions under specific sensing conditions, particularly at $\mathrm{pH}$. Ultra-trace concentrations of $\mathrm{Hg}$ (II) ions were easily detected with the naked eye using the OSM. The remarkable ion spectral response of $\mathrm{Hg}$ (II) ion-OSM ensured the excellent quantification of the OSM for $\mathrm{Hg}(\mathrm{II})$ ion sensing over a wide range of concentrations with a detection limit of $1.75 \times 10^{-9} \mathrm{M}$. This result indicated that low concentrations of $\mathrm{Hg}$ (II) ions can be detected with a high sensitivity. One of the key issues of OSM is the $\mathrm{Hg}$ (II) ion-selective workability even in the presence of high doses of competitive matrices and species. The OSM design
\end{abstract}


showed significant $\mathrm{Hg}$ (II) ion-sensing capability despite the number of reuse/recycles using simple decomplexation. Given its high selectivity, fast response, and sensitivity, the OSM could be developed into a specific $\mathrm{Hg}(\mathrm{II})$ ion-sensing kit in aqueous solutions.

Keywords: silica nanotube; OSM; $\mathrm{Hg}(\mathrm{II})$ ion sensing; water; optical detection and recognition

\section{Introduction}

The selective and sensitive detection of toxic heavy metal ions is important because of their negative effects on human health and the environment [1-6]. Among these ions, $\mathrm{Hg}$ (II) is the most ubiquitous because of its high toxicity and bioaccumulation [7-10]. $\mathrm{Hg}(\mathrm{II})$ is highly hazardous because both elemental and ionic $\mathrm{Hg}$ can be converted by bacteria in the environment into methylmercury, which is subsequently bioaccumulated along the food chain. High exposure to $\mathrm{Hg}$ (II) affects the brain and its associated functions, causing irritability, nervousness, tremors, vision problems, deafness, and the loss of muscle coordination, sensation, and memory. Methylmercury also damages the kidneys, stomach, heart, and intestines [11-13]. According to World Health Organization guidelines, the concentration of $\mathrm{Hg}(\mathrm{II})$ in drinking water must be below $2 \mu \mathrm{g} / \mathrm{L}$ [12]. Therefore, the development of highly sensitive and selective methods for the timely and accurate removal and monitoring of trace $\mathrm{Hg}$ (II) is urgently needed. Currently used analytical methods to monitor low $\mathrm{Hg}$ (II) levels include inductively coupled plasma mass spectrometry, ion-selective electrodes, atomic absorption spectrometry, and atomic fluorescence spectroscopy [14-18]. However, the applications of these methods are limited by their time-consuming process, high cost, low sensitivity and selectivity, and complicated sample preparation. To avoid these problems, we designed a new method with simple operation, rapid completion, low consumption, high sensitivity and selectivity, and possible applications in field tests and on-site $\mathrm{Hg}$ (II) monitoring [19-22]. Chemical precipitation, ion exchange, filtration, electrochemical separation, reverse osmosis, evaporative recovery, solvent extraction, and adsorption have been used to remove and preconcentrate heavy metal ions from water resources [23-29]. Among these techniques, adsorption is the most promising because of its low operational and maintenance costs; however, the potential of this method is limited by its low efficiency to completely remove heavy metal ions at low concentrations without the preconcentration process [19-22]. High-performance adsorbents have attracted increasing attention because of their capacity to remove toxicants and detect ultra-trace concentrations of these species [2-8,19-22].

Mesoporous inorganic monolithic membranes have received considerable interest in the last two decades because of their uniform and tunable pores with 2 and 3D hexagonal and cubic geometrical structures, thermal/ hydrothermal stability in organic and inorganic phases [30-33]. These mesoporous micrometric-size particle-like monoliths have many potentialities in control design of membrane applications in wide-range fields running from separation [34-36], catalysis [37,38] gas sensing [39] energy storage devices [40] to adsorption [2-8,19-22], Among these nanomaterials, 1D nanoscale channel-based materials have gained attention in recent years because of their unique electronic, optical, and mechanical properties as well as great potential for nanotechnology applications [41-44]. New 
types of hierarchical membrane materials for various industrial filtration applications have been synthesized [45-50]. Since Martin [44] discovered 1D nanochannels inside anodic alumina membranes (AAMs), controlled architecture over arranged armed pores and uniformly shaped nanochannel dimensions has led to vast advancements in materials science [45-50]. Particularly, 2D hexagonal and 3D cubic mesoporous silica mesostructures with pore sizes of 3-17 $\mathrm{nm}$ range hybrid the columnar pores of AAM nanochannels have been fabricated through template-guided methods using amphiphiles; these materials differ in character and structure under various conditions, leading to efficient size-exclusion separation and molecular transport technology [50]. In well-controlled environments, the detection of hazardous in the real-life environments particularly that associated in low level of concentration is crucial [51]. Thus, control design of optical chemical sensing is unquestionable. In this systematic optical sensor design, the color changes of the receptors are induced via nonspecific interaction with ion hazardous species, indicating significant signaling and selective response to the hazardous species [51-58]. Effective mesoporous sensor designs have enabled researchers to control assessment of sensing and removal techniques for continuously tracking pollutants up to nanomolar concentrations via visual color changes. In such systematic mesoporous sensor architectures, anchoring organic ligands into inorganic networks with well-defined pores promotes the sensibility of toxic analytes. However, the development of simple solid sensors for the selective detection of toxic ions in basic laboratory assays remains challenging [2-8,52-58].

In this study, silica nanotubes (NTs) with hexagonally ordered mesopores $(6 \mathrm{~nm})$ inside hybrid AAM channels were decorated by an organic dye probe without distorting the mesostructure geometry inside the NTs. An optical sensor membrane (OSM) was fabricated by imbuing the surfaces and pores of the NTs with organic scaffolds that can detect $\mathrm{Hg}$ (II) within 2-3 min. The decoration or covering the interior NTs by organic dye layers that are chemically stable and selectively active binding to target ions led to transport nonselective target species without absorption or binding with the NT wall (Scheme 1). The OSM offers $\mathrm{Hg}$ (II) ion-selective workability even in the presence of high doses of competitive matrices and species under specific sensing conditions, particularly at $\mathrm{pH}$. The OSM also enables the development of a simple, portable, and reusable chemical sensing device even under rigorous chemical treatment despite the number of reuse/recycles.

\section{Experimental Section}

\subsection{Chemicals}

All materials were analytical grade and used as purchased without further purification. Tetramethylorthosilicate (TMOS), Brij76 [ $\left.\mathrm{C}_{18} \mathrm{H}_{35}\left(\mathrm{OCH}_{2} \mathrm{CH}_{2}\right)_{10} \mathrm{OH}\right]$, dodecane $\left(\mathrm{C}_{12}\right.$-alkane), and the organic dye diphenylthiocarbazone (DPTZ) were purchased from Sigma-Aldrich Company Ltd. (St. Louis, MO, USA). Hg(II) and other metal ion-standard solutions were obtained from Wako Company Ltd. (Osaka, Japan). The concentration of $\mathrm{Hg}$ (II) ions was calculated by comparing the color intensity of OSM after detecting $\mathrm{Hg}$ (II) samples and standard $\mathrm{Hg}$ (II) ion samples, which were prepared with known concentrations of $\mathrm{Hg}$ (II) analyte solutions. AAM with a pore size of $200 \mathrm{~nm}$, a diameter of $2.5 \mathrm{~cm}$, and a thickness of $60 \mu \mathrm{m}$ was purchased from Whatman, Co. Ltd. (Maidstone, UK). 


\subsection{Synthetic Design of OSM}

Mesoporous silica NTs inside the AAM nanochannels were fabricated through a direct method. The first step was the formation of microemulsion liquid crystalline phases, in which $1.0 \mathrm{~g}$ of Brij76, $0.5 \mathrm{~g}$ of dodecane, $2 \mathrm{~g}$ TMOS, $1.25 \mathrm{~g}$ of $\mathrm{H}_{2} \mathrm{O}-\mathrm{HCl}$, and $10 \mathrm{~g}$ of ethanol were applied dropwise onto the AAM nanochannels. The penetration of the precursor solution into the membrane was achieved within a vacuum at a starting pressure of $\leq 0.04 \mathrm{MPa}$. For the second step, silica NTs were cast along the entirety of the AAM nanochannel islands under suction, controlling the deposition of the surfactant/silica-NTs onto the inner pores of the AAM. The hybrid organic-inorganic membrane was placed in a sealed container at $45{ }^{\circ} \mathrm{C}$ for $10 \mathrm{~h}$ to complete drying. In the third step, the hybrid organic-inorganic membrane was thoroughly washed several times in a Soxhlet apparatus using ethanol/acidified $\mathrm{H}_{2} \mathrm{O}$ to remove the surfactant template and then dried at $60{ }^{\circ} \mathrm{C}$ [46,52]. The resulting materials were calcined at $550{ }^{\circ} \mathrm{C}$ under air. The solid scaffolds can be used to immobilize a $100 \mathrm{~mL}$ ethanolic solution of $45 \mathrm{mg}$ DPTZ. The solution was directly dispersed or exposed to $1 \mathrm{~g}$ of the scaffold under static conditions at $50{ }^{\circ} \mathrm{C}$ for $10 \mathrm{~h}$. DPTZ immobilization was repeated several times until the equilibrium adsorption capacity or "saturation" of the DPTZ molecule into the silica NTs was achieved. The resultant OSM was thoroughly washed with deionized water until no elution of the DPTZ into the solution was observed. The released/eluted DPTZ color was detected by measuring the absorbance spectra at $K_{\max }=445 \mathrm{~nm}$ (Scheme 1).

\subsection{Instrumental Analysis}

High-resolution transmission electron microscopy (HRTEM) was performed using a JEOL JEM model 2100F microscope. Energy dispersive X-ray spectroscopy (EDS) was conducted using a Horiba EDS-130S directly connected with a Hitachi FE-SEM S-4300. FE-SEM images were measured using a field-emission scanning electron microscope (Hitachi S-4300). Small-angle powder X-ray diffraction (XRD) patterns were measured by using a $18 \mathrm{~kW}$ diffractometer (Bruker D8 Advance) with monochromated $\mathrm{CuK} \alpha$ radiation and with scattering reflections recorded at $2 \theta$ angles between $0.1^{\circ}$ and $6.5^{\circ}$ corresponding to d-spacing between 88.2 and $1.35 \mathrm{~nm} . \mathrm{N}_{2}$ adsorption-desorption isotherms were measured using a BELSORP MIN-II analyzer (JP. BEL Co. Ltd, Osaka, Japan) at $77 \mathrm{~K}$. The pore size distribution was determined from the adsorption isotherms through nonlocal density functional theory. The absorbance spectrum of the OSM was obtained using a UV-Vis-NIR spectrophotometer (Shimadzu 3700). $\mathrm{Hg}(\mathrm{II})$ ion concentrations were determined via inductively coupled plasma atomic emission spectrometry (ICP-MS, Perkin Elmer Elan-6000).

\section{Results and Discussion}

\subsection{Building Design of OSM Architectures}

Mesoporous silica NTs with a mesocylinder pore of approximately $6 \mathrm{~nm}$ inside AAM channels of $200 \mathrm{~nm}$ neck pores may serve as a new class of membranes with toxic ion-sensing functionality. However, the functionalization of vertically aligned silica NTs casting nanochannels with a large area-to-volume ratio and uniformly-packed mesopores led to the dense connection and condensed 
decoration of DPTZ into NTs and then to the formation of interior coating layers for $\mathrm{Hg}$ (II) ion-selective species from water (Scheme 1). The design of OSM with macroscopic length disc $(2.5 \mathrm{~cm})$ and ordered mesopores inside NTs was based on sufficiently physisorbed interactions (Scheme 2) between the silanol groups of silica NTs and the heteroatoms of DPTZ. This process led to the high loading capacity and accessibility of the DPTZ probe. Moreover, the long-term dispersion time and deep cavitation of DPTZ into $>>20 \mu \mathrm{m}$ channel length offer the required interactions with the NT wall to prevent the leaching of probe receptors from the OSM disc. No elution of the OSM platforms occurred during the detection of $\mathrm{Hg}$ (II) ions in aqueous solutions (Scheme 1E-F). These results indicated that the stability of the fabricated OSM incorporated with DPTZ may enhance the fast response optical color signal, $\mathrm{Hg}(\mathrm{II})$ ion-stripping under severe condition of reuse/recycles, and selectivity of $\mathrm{Hg}(\mathrm{II})$ ions among competitive matrices and species (Scheme 1).

Scheme 1. Schematic of mesoporous silica NT-supported anodic alumina membranes (AAM) channels (A-C), optical sensor membrane (OSM) (D), and ion-sensing functionality processes in terms of visualization $(\mathbf{E})$, stripping $(\mathbf{G})$, and selectivity $(\mathbf{F})$. The silica nanotube (NT) scaffolds were fabricated through template-assisted synthesis, in which the chemical composition containing Brij/alkane/TMOS/ethanol/ $\mathrm{H}_{2} \mathrm{O}$ could be penetrated through AAM channels by a pressure-assisted method (A, B). The calcined NT/AAM (C) could be used to synthesize OSM through the stepwise immobilization of DPTZ (D). Bench-top contact method for controlling the optical $\mathrm{Hg}$ (II) ion-screening/sensing in water using OSM (E-F).

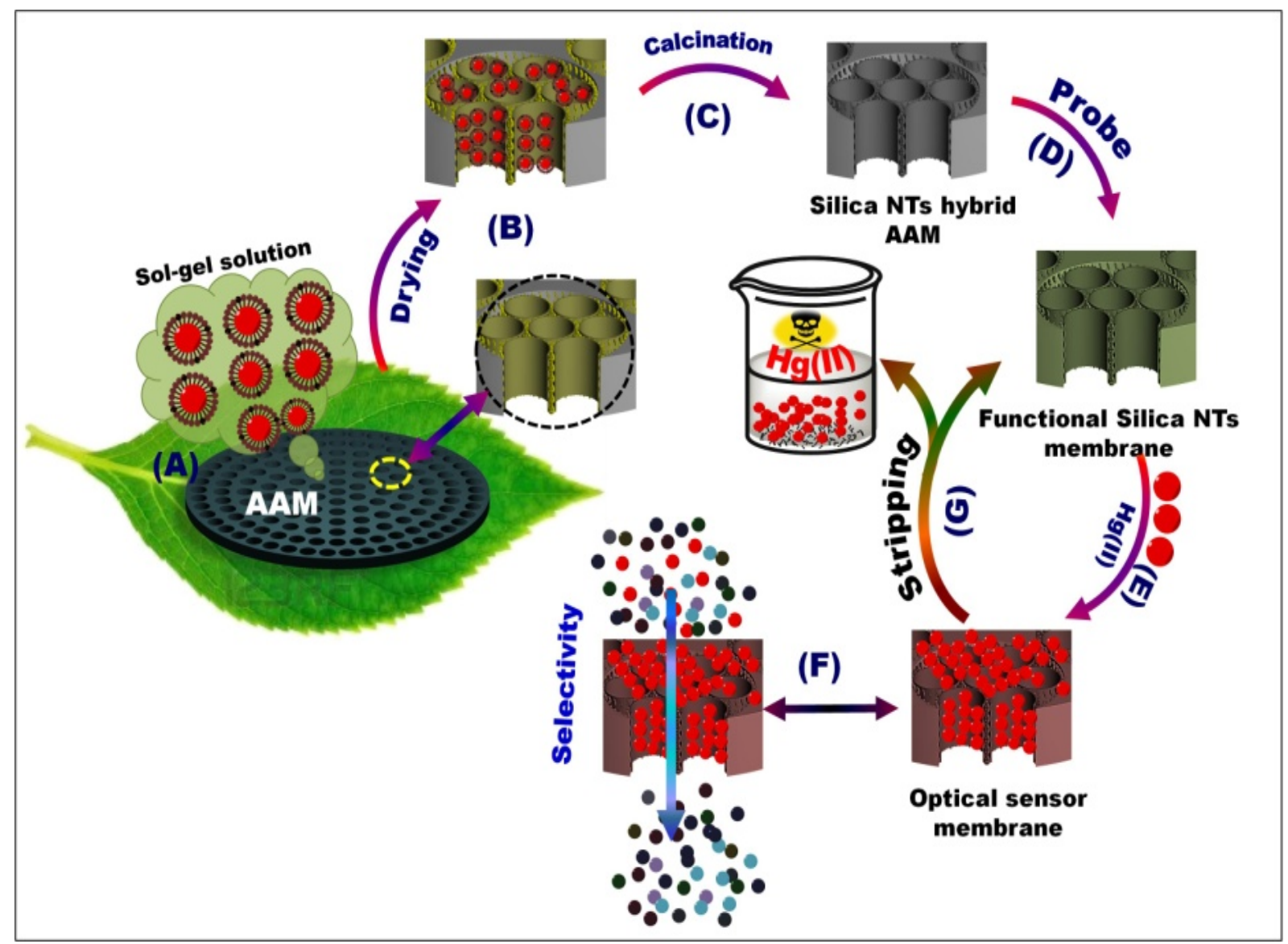




\subsection{Characterization of the Fabricated OSM Architectures}

NT scaffolds and OSM were successfully fabricated, as evidenced by HRTEM and SEM micrographs (Figure 1A,B), EDM analyses (Figure 1C), and XRD and N2 isotherm profiles (Figure 1D,E). High-resolution TEM (HR-TEM) images (inset in Figure 1A) showed that each NT had ordered mesoporous arrays circularly arranged around the tube axis in the OSM. The OSM NTs clearly contained open pores with regular and continuous alignment along the perpendicular axis of the AAM host surfaces. SEM images (Figure 1B) revealed that this synthetic design allowed the control of the vertical alignment of the silica NTs parallel to the axis of the AAM nanochannels. We observed rigid, free-standing OSM clearly featuring open pores with regular and continuous alignment along the perpendicular axis scaffold platforms. The results clearly indicated the formation of condensed mesoporous OSM NTs, permitting the ion-sensing and removal of toxicants from water. EDS analysis (Figure 1C) revealed the presence of $\mathrm{Si}, \mathrm{Al}, \mathrm{O}, \mathrm{C}, \mathrm{S}$, and $\mathrm{N}$ in the fabricated OSM. The EDS, TEM, and SEM results indicated that the decoration of DPTZ and the formation of OSM occurred via deep accommodation into the entire mesopore NTs/AAM and with orientational axis parallel to NTs [50].

Figure 1. HRTEM micrograph patterns of the OSM (A). FESEM micrographs of the OSM (B) and EDS of the fabricated OSM indicate the presence of Si, Al, O, C, S, and N (C). Small-angle XRD patterns (D); $\mathrm{N}_{2}$ adsorption/desorption isotherms (E) of the silica NTs/AAM scaffolds (a), OSM fabricated by immobilization of the DPTZ probe on silica NTs scaffolds (b), and OSM after $\mathrm{Hg}$ (II) ion screening/sensing (c).
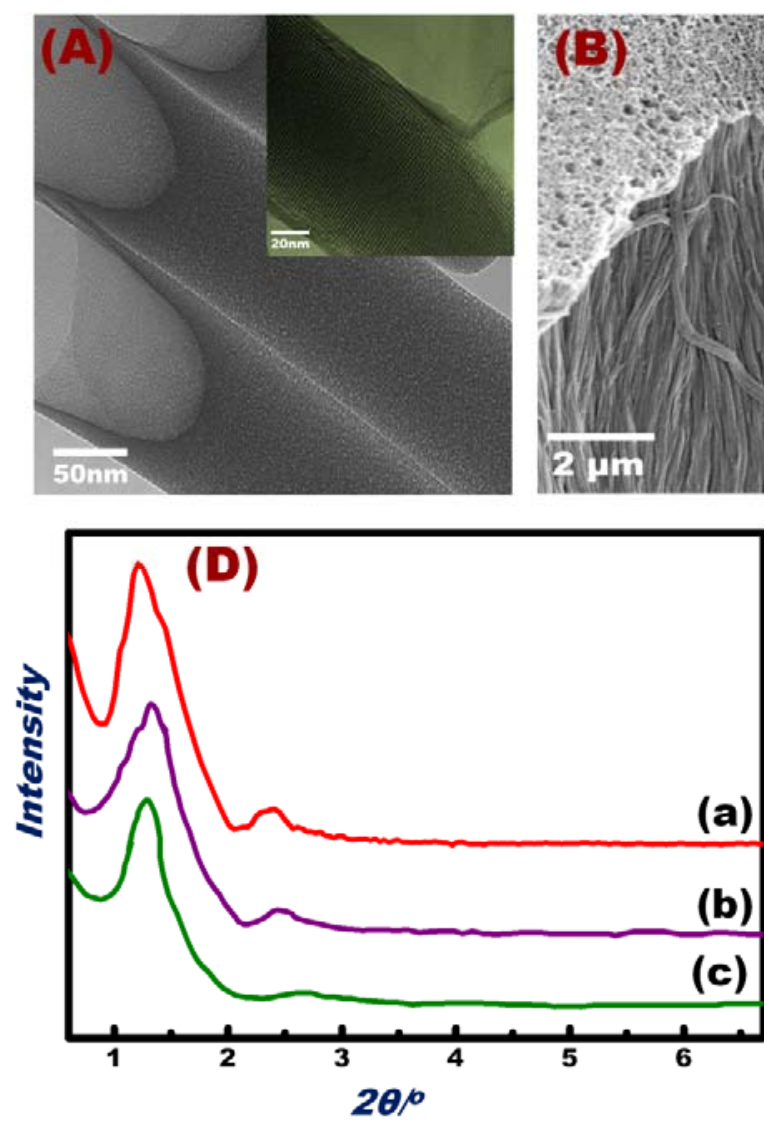
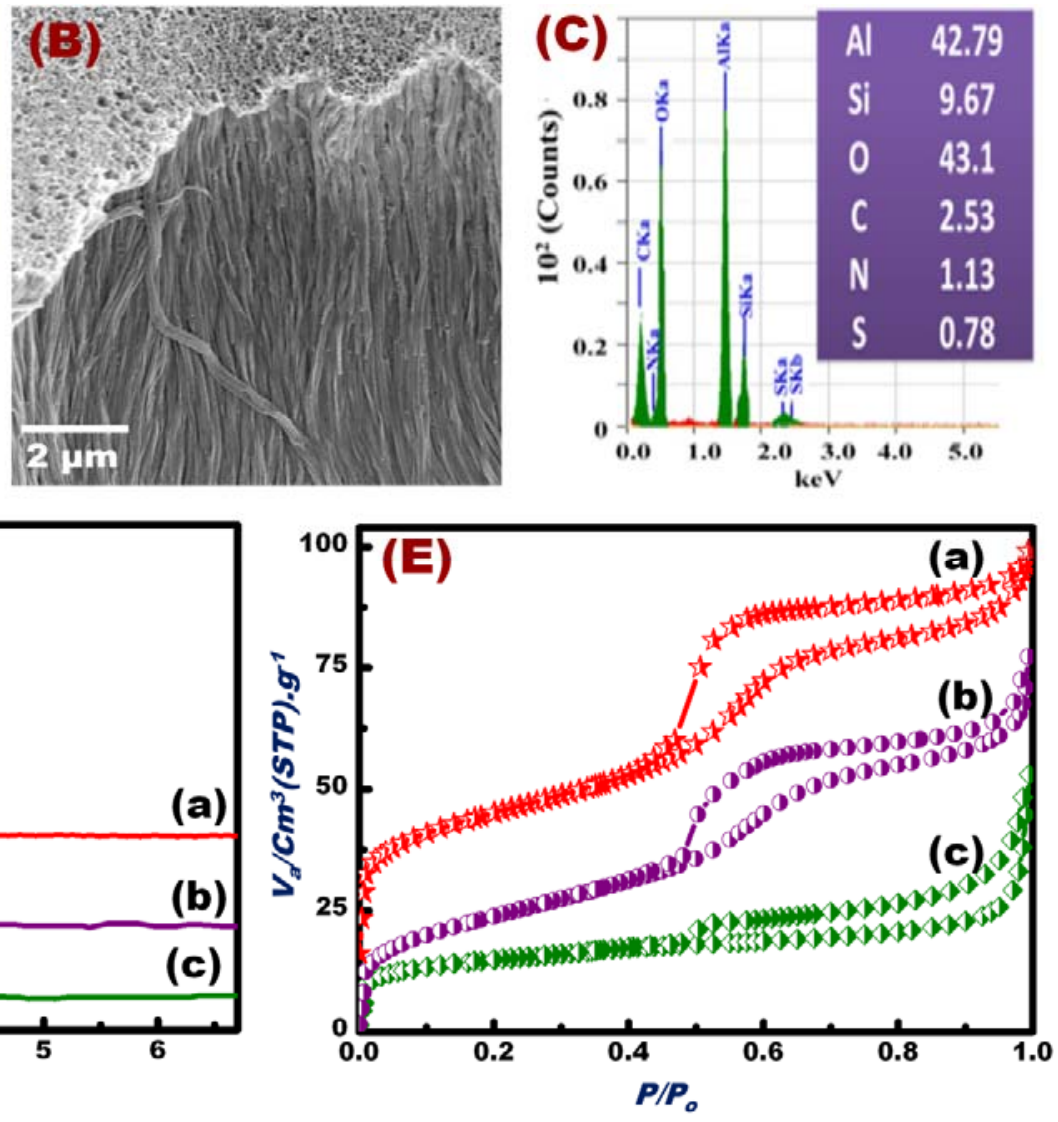
The XRD patterns of the hexagonal silica NTs/AAM scaffolds and OSM are shown in Figure 2D. Reflection peaks with high-intensity and well-defined resolution were observed in the range of $1.2<2 \theta<3.0$, which strongly suggested the formation of ordered hexagonal mesostructures of scaffolds and OSM with 100 and 110 reflection planes (Figures 1Da-Dc). The high-intensity peak of OSM patterns (Figures 1Db,Dc) shifted to a high $2 \theta$, which indicated the immobilization of DPTZ in the interior of the NT mesopores. In general, the XRD profiles indicated the retention of the hexagonal structure of OSM despite the immobilization of DPTZ probes in the inner pores of the NTs and the multiple uses of OSM for $\mathrm{Hg}(\mathrm{II})$ detection/removal (Figure 1Dc). $\mathrm{N}_{2}$ adsorption isotherms also implied mesoporous OSM formation (Figure 1E). The $\mathrm{N}_{2}$ isotherms (Figure 1E) showed well-defined isotherm steepnesses, indicating the formation of channel-like mesopores with no constrictions. The isothermal shape and capillary evaporation indicated the formation of uniform cylinder-like structures. Consequently, the presence of large hysteresis H1 and H3 loops (Figure 1Ec) for typical hexagonal mesocylinder materials was revealed. This result coincided with previous studies on bulk mesoporous materials functionalized with organic molecules [59-62]. Table 1 shows the Brunauer-Emmett-Teller surface area (SBET), pore volume $\left(\mathrm{V}_{\mathrm{p}}\right)$, and pore diameter $(\mathrm{D})$ of the support material modified with organic scaffolds and after multiple uses for $\mathrm{Hg}$ (II) ion screening/sensing. Upon DPTZ immobilization, the surface area and pore volume of the material slightly decreased (Table 1), and the width of the hysteresis loop reduced (Figure 1Eb,1Ec). This result indicated the inclusion of the probe within the inner pores of the OSM. The OSM demonstrated high affinity binding with $\mathrm{Hg}$ (II) ions, as evidenced by the color reactions for trace $\mathrm{Hg}(\mathrm{II})$ concentrations. These reactions were clearly visible to the naked eye (see Section 3.3).

Table 1. $\mathrm{N}_{2}$ adsorption parameters of silica NTs (a), OSM fabricated by immobilization of the probe on silica NTs (b), and OSM after $\mathrm{Hg}(\mathrm{II})$ ion screening.

\begin{tabular}{cccc}
\hline Material & $\mathbf{S}_{(\mathbf{B E T})} \mathbf{~ m}^{2} / \mathbf{g}$ & $\mathbf{V}_{\mathbf{p}} \mathbf{~ c m}^{3} / \mathbf{g}$ & $\mathbf{D} / \mathbf{n m}$ \\
\hline Silica NTs & 130 & 0.66 & 6.1 \\
Silica NT-Captor & 70 & 0.60 & 5.7 \\
Silica NT-Captor/Hg & 40 & 0.40 & 5.2 \\
\hline
\end{tabular}

\subsection{Optical Screening/Sensing of Hg(II) Ions Using OSM}

The optical screening/sensing of $\mathrm{Hg}$ (II) ions in water using OSM was assessed by the top-bench contact time technique. Under this protocol, the OSM was fixed in an ordinary filtration apparatus under static conditions (Scheme 1). A mixture containing specific concentrations of $\mathrm{Hg}$ (II) ions was adjusted at appropriate $\mathrm{pH} 5$ solutions at a constant volume $\left(20 \mathrm{~cm}^{3}\right)$ and then added to the OSM. After approximately 2 min of response time, the solution was filtrated under gentle vacuum at $0.04 \mathrm{MPa}$ and room temperature. The aliquot/rejected solution was collected and monitored by ICP-MS. The color change of the solid OSM indicated the visual detection and quantitative recognition of $\mathrm{Hg}$ (II) ions (Schemes 1 and 2). 
Scheme 2. The chemical formation of [Hg-DPTZ)2] complex during the selective ion-OSM sensing conditions. The feasibility of reusing OSM was obtained by addition of $0.05 \mathrm{M}$ of $\mathrm{ClO}_{4}^{-}$solution as stripping agent.
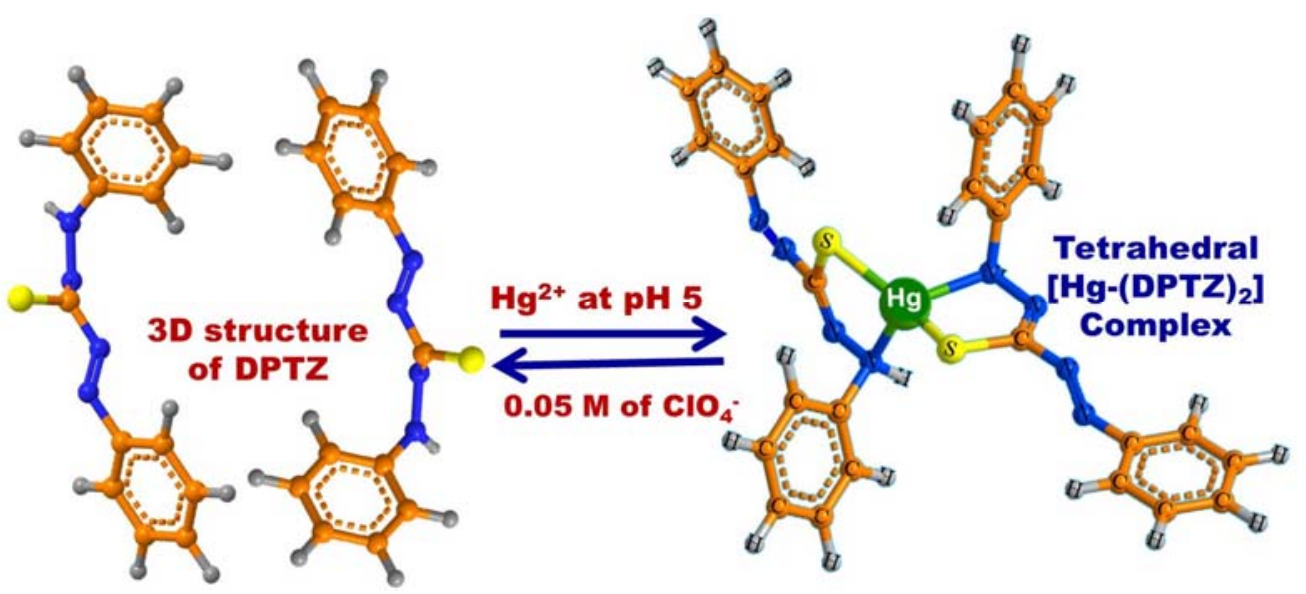

To control the optimal sensing experiment conditions, particularly $\mathrm{pH}$, batch sensing experiments were performed at a wide range of $\mathrm{pH}(2-12)$ (Figure 2A). The different $\mathrm{pH}$ values were established by mixing $0.2 \mathrm{M} \mathrm{KCl}$ with $\mathrm{HCl}$ ( $\mathrm{pH}$ 1-3), $\mathrm{CH}_{3} \mathrm{COONa}$ with $\mathrm{CH}_{3} \mathrm{COOH}$ (pH 4-6), 3-morpholinopropane sulfonic acid with $\mathrm{NaOH}(\mathrm{pH}$ 6.5-8.5), and N-cyclohexyl-3-aminopropane sulfonic acid with $\mathrm{NaOH}(\mathrm{pH}$ 9-12). To determine the optimum $\mathrm{pH}$ for the donor-acceptor combinations between the OSM and $\mathrm{Hg}$ (II) ions, the reflectance spectra of the formed $\mathrm{Hg}$ (II)-DPTZ binding events on OSM were carefully monitored over a wide range of $\mathrm{pH}$ solutions. The DPTZ immobilized on the silica NTs had different donor atoms, such as N and S, which can be neutral or protonated, depending on the $\mathrm{pH}$ of the medium that can form metal complexes because of a deficiency in the d-orbitals of the metal ion centers (Scheme 2) [54,55]. UV-vis reflectance spectra were used to monitor the changes in the OSM color upon the formation of the $\left[\mathrm{Hg}-(\mathrm{DPTZ})_{2}\right]$ complex (Scheme 2). The maximum changes in the color and reflectance spectra of OSM implied the sensitive and flexible changes in the electronic structure of the DPTZ at $\mathrm{pH}$ 5. The change in the color and reflectance intensity of the $\left[\mathrm{Hg}-(\mathrm{DPTZ})_{2}\right]$ complex was recorded at $\lambda_{\max }=485 \mathrm{~nm}$ and at $\mathrm{pH} 5$. The effect of $\mathrm{Hg}$ (II) ion concentration on the reflectance spectra and sequential color response of OSM at $\mathrm{pH} 5$ was examined (Figure 2B). The prompt reflectance spectral responses by OSM showed the effective detection of $\mathrm{Hg}$ (II) ions at $\kappa_{\max }=485 \mathrm{~nm}$, with color transitions at a frequency that could be detected by the naked eye even at trace concentrations [51-58].

Figure 2C shows the calibration curve of $\mathrm{Hg}$ (II) ion-OSM. The quantitative analysis (i.e., calibration curve) depicted the reflectance spectral responses of the OSM as function of $\operatorname{Hg}$ (II) ion concentrations under optimized sensing conditions of 2 min contact time, $\mathrm{pH} 5$, and $20{ }^{\circ} \mathrm{C}$ temperature. The $R-R_{0}$ relationship was obtained by measuring the relative reflectance of the $\left[\mathrm{Hg}-(\mathrm{DPTZ}]_{2}\right]^{n+}$ complex $(R)$ formed relative to a blank solid of OSM $\left(R_{0}\right)$. The limit of detection (LOD) of the OSM for $\mathrm{Hg}(\mathrm{II})$ ions estimated from the linear part of the calibration curve according to the following equation $L O D=k S_{b} / m$, where $S_{b}$ and $m$ are the standard deviation and the slope of the calibration curve, respectively, and the constant $k$ is 3 . The $L O D$ of OSM at a particular $\mathrm{pH}$ was calculated to be $1.75 \times 10^{-9} \mathrm{M}$ for $\mathrm{Hg}(\mathrm{II})$ ions, indicating of the efficiency of the $\mathrm{Hg}(\mathrm{II})$ ion-sensing 
method for the estimation and detection of trace $\mathrm{Hg}$ (II) ion concentrations. Thus, the proposed method may be appropriate for household and environmental monitoring [62].

Figure 2. $\mathrm{pH}$-dependent curves of OSM in the measurement of the reflectance spectra "signal" response and the color profiles of the [Hg-(DPTZ) 2$]$ complex during the optical screening of $\mathrm{Hg}(\mathrm{II})$ ions at $485 \mathrm{~nm}$ (A); Reflectance spectra and sequential color response of OSM at different concentrations of $\mathrm{Hg}$ (II) ions at $\mathrm{pH} 5$ (B). Calibration curve of the reflectance spectra of OSM for various $\mathrm{Hg}$ (II) concentrations at $485 \mathrm{~nm}$. The inset in the graph shows the low-limit colorimetric responses of $\mathrm{Hg}$ (II) ions with a linear fit line in the linear concentration range before saturating the calibration curve (C). The solid line represents the calibration curve of the $\mathrm{Hg}$ (II) ions in the presence of active interfering species [i.e., $\mathrm{Co}(\mathrm{II}), \mathrm{Mn}(\mathrm{II}), \mathrm{Cu}(\mathrm{II}), \mathrm{Zn}(\mathrm{II}), \mathrm{Fe}(\mathrm{III})$, and $\mathrm{Ni}(\mathrm{II})]$ under the same sensing/screening conditions.

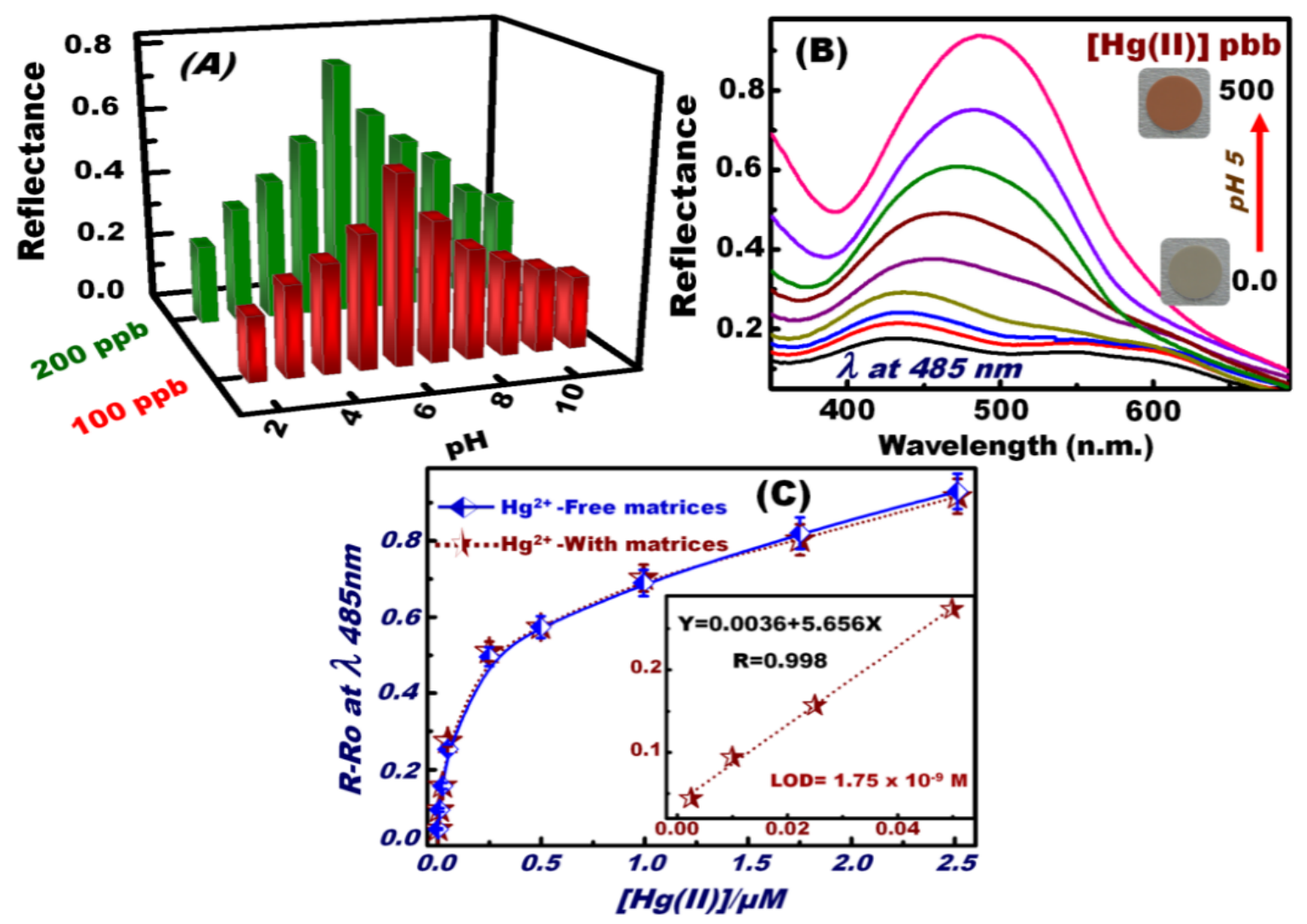

\subsection{Feature and Functionality of the Hg(II) Ion-OSM Sensing System}

An important analytical feature of OSM is its response time, which is controlled by the time required for $\mathrm{Hg}(\mathrm{II})$ ions to diffuse from the bulk of the solution to the OSM interface to form $\mathrm{Hg}$ (II)-DPTZ complexes. Figure 3 shows the effect of time on $\mathrm{Hg}$ (II) ion sensing/screening at $\mathrm{pH} 5$, $20{ }^{\circ} \mathrm{C}$, and different $\mathrm{Hg}$ (II) ion concentrations (20, 50, and $200 \mathrm{ppb}$ ), as determined by ICP-MS analysis. With prolonged time, the equilibrium concentration of $\mathrm{Hg}(\mathrm{II})$ ions decreased. This decrease in concentration resulting from the uptake of $\mathrm{Hg}(\mathrm{II})$ into the OSM decreased the diffusive transport of the $\mathrm{Hg}(\mathrm{II})$ ions. The OSM under optimum sensing conditions reached more than $95 \%$ of its uptake at 2 min. In addition, the change in the reflectance signaling and color transition (Figure 3B) was 
proportional to the concentration of metal ion uptake into solid OSM. In this solid analysis, the increase in the reflection spectra as a function of time indicated the adsorption of $\mathrm{Hg}$ (II) ions into the NT cavity of the OSM.

Figure 3. Effect of time on the uptake of $\mathrm{Hg}(\mathrm{II})$ on the OSM at different $\mathrm{Hg}$ (II) concentrations. The inset shows the reflectance spectra for OSM (blank) and OSM-Hg(II) ions uptake at $\mathrm{pH} 5$ and color transition map tested at the total volume of $20 \mathrm{~mL}$ and temperature of $20^{\circ} \mathrm{C}$.

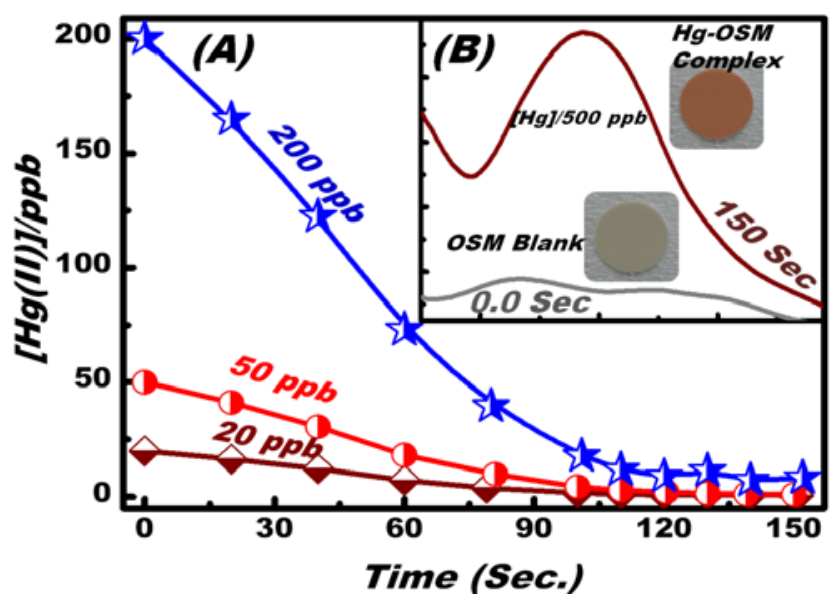

Figure 4. Selectivity studies of OSM for [500 ppb] $\mathrm{Hg}(\mathrm{II})$ ion removal carried out in groups

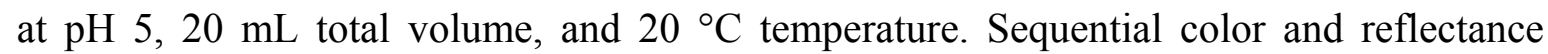
signaling at characteristic $\lambda_{\max }=485 \mathrm{~nm}$, indicating the response to the OSM sensor (blank, i.e., metal-free assay) and with the addition of interfering cationic species and target ions.

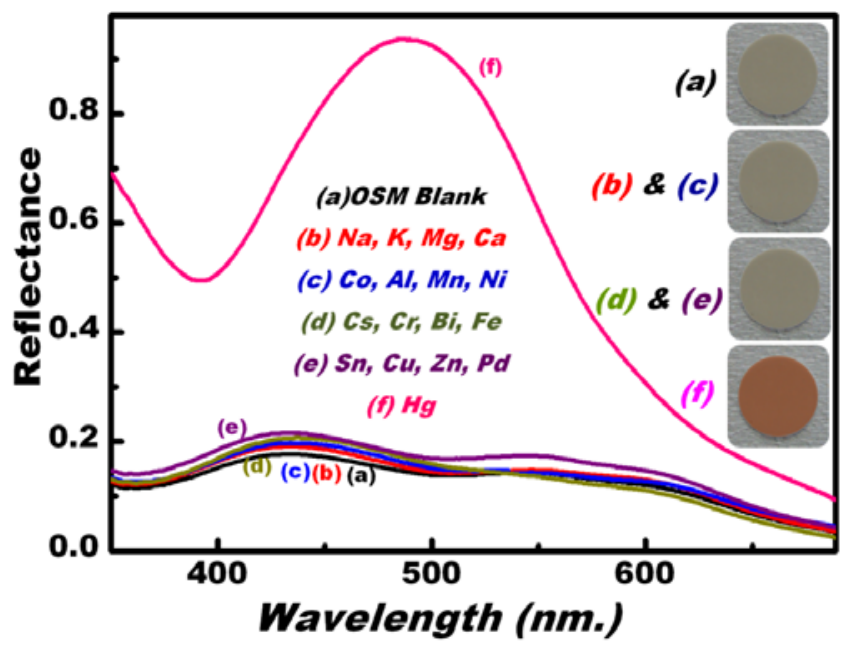

One of the main characteristics of OSM technology is its ion-sensitive selectivity to the target $\mathrm{Hg}$ (II) ions. Figures $2 \mathrm{~B}$ and $3 \mathrm{~B}$ (inset) show that the OSM can be used as an optical kit to yield preconcentration efficiency, allowing the visual inspection and rapid monitoring of a wide range of $\mathrm{Hg}$ (II) ion concentrations, including ultra-trace concentrations (Figure 2B). We studied the potential selectivity of our material in the presence of interfering cations at $\mathrm{pH} 5$ (Figure 4). No significant changes were observed in the visible color patterns and the reflectance spectra of the OSM (blank) 
even after adding high concentrations of various competitive ions. This result indicated that the negative disturbance affected OSM. We examined the specificity of OSM by assessing its capacity to selectively detect $\mathrm{Hg}$ (II) ions in the presence of a multi-metal interference system under optimum sensing conditions (Figure 4). No obvious changes were detected in the visible color or reflectance patterns in the presence of other interfering species, even at high loading levels [5 to 10 times the amounts of $\mathrm{Hg}(\mathrm{II})$ ions]. This result indicated the rapid binding response and stability of $\mathrm{Hg}(\mathrm{II})-\mathrm{OSM}$ complexes within the pore surfaces, which allowed the selective determination of toxic ions in real samples [2-8].

A key component of OSM is its reversibility against repeated uses (Scheme 2), thereby allowing the multiple reuse of OSM. This OSM feature can significantly reduce reagent consumption. The main objective of this study is to determine a method to efficiently control the reuse of our engineered OSM (Scheme 1 and 2). Sensing experiments with reuse/recycle were performed under the $\mathrm{Hg}$ (II) ion selective conditions of $20{ }^{\circ} \mathrm{C}, \mathrm{pH} 5,20 \mathrm{~mL}$ total volume, $1 \mathrm{ppm}[\mathrm{Hg}(\mathrm{II})]$, and 2 min response time. $\mathrm{Hg}$ (II) ion-OSM regeneration was carried out through a chemical treatment process, in which a specific concentration of $\mathrm{Hg}$ (II) ion stripping agent was added with a minimum volume and concentration. The best results were obtained using a $0.05 \mathrm{M} \mathrm{ClO}_{4}{ }^{-}$solution, which permits complete regeneration in an optimally reasonable conditioning time (i.e., $15 \mathrm{~min}$ ) (Scheme 2). The feasibility of reusing OSM after a number of sensing/capturing and regeneration cycles was investigated (Figure 5). After eight regeneration/reuse cycles, the reflectance slightly decreased. This result indicated that a slight decrease in efficiency can slightly affect the overall efficiency of the OSM.

Figure 5. Multiple reuse cycles of the sensor for $\mathrm{Hg}$ (II) ions after eight regeneration/ reuse cycles (the reusability efficiency was measured compared to the first cycle at $\lambda \max =485 \mathrm{~nm}$, inset). Experiments were performed under the following conditions: $\mathrm{pH} 5$, total volume $20 \mathrm{~mL}$, and temperature at $20^{\circ} \mathrm{C}$; [Hg(II)] of $500 \mathrm{ppb}$.

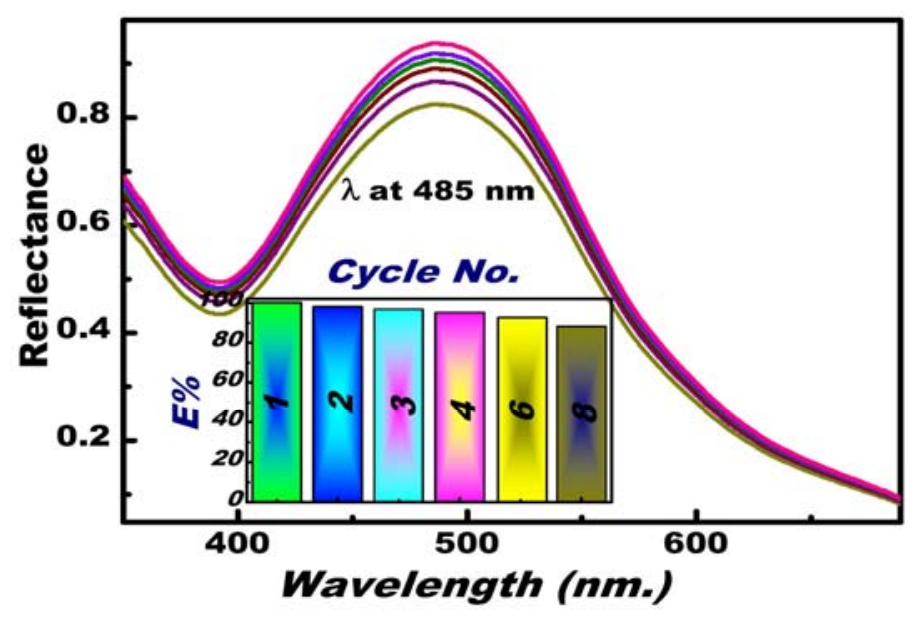

\section{Conclusions}

We report the design and engineering of OSM based on the tailored channel arrays of hexagonal mesocylinder silica NTs inside AAM. In solid-state ion-sensing systems, the physical features of OSM, such as the large surface area-to-volume ratios of the modified layers of organic scaffolds and the uniform pores, enabled the synthesis of a multi-particulate sensing system for the highly selective 
and sensitive optical screening and fast-response monitoring of $\mathrm{Hg}$ (II) ions, even at trace concentrations, in drinking water. The constructed sensory system can be repeatedly used in aqueous solutions. Thus, our OSM design can continuously generate readable optical signals, which are suitable for reporting recognition events without the need for other treatments or complex instruments.

\section{Author Contributions}

The present work is designed to pursuit Professor Sherif' Lab goals, motivation, and research variety in the environmental field. This research work introduces the idea of Prof. Sherif; however, the other Authors effectively achieved the experimental facts towards goal attainment. All Authors are shared in discussion, writing down the texture body of the manuscript.

\section{Conflicts of Interest}

The present findings of research impacts show the real degree of variety among all presented work reported by the Authors and other groups. We here declare that there is no confliction of interests in this research work.

\section{References}

1. Bessbousse, H.; Rhlalou, T.; Verchere, J.-F.; Lebrun, L. Sorption and filtration of Hg (II) ions from aqueous solutions with a membrane containing poly (ethyleneimine) as a complexing polymer. $J$. Membr. Sci. 2008, 325, 997-1006.

2. El-Safty, S.A.; Prabhakaran, D.; Ismail, A.A.; Matsunaga, H.; Mizukami, F. Three-dimensional wormhole and ordered mesostructures and their applicability as optically ion-sensitive probe templates. Chem. Mater. 2008, 20, 2644-2654.

3. El-Safty, S.A.; Shenashen, M.A.; Ismael, M.; Khairy, M.; Awual, M.R. Optical mesosensors for monitoring and removal of ultra-trace concentration of $\mathrm{Zn}(\mathrm{II})$ and $\mathrm{Cu}(\mathrm{II})$ ions from water. Analyst 2012, 137, 5208-5214.

4. Khairy, M.; El-Safty, S.A.; Shenashen, M.A. Envirnmental remediation and monitoring of cadmium. TrAC Trends Anal. Chem. 2014, 62, 56-68.

5. El-Safty, S.A.; Ismail, A.A.; Matsunaga, H.; Mizukami, F. Optical nanosensor design with uniform pore geometry and large particle morphology. Chem. Eur. J. 2007, 13, 9245-9255.

6. Elshehy, E.A.; El-Safty, S.A.; Shenashen, M.A.; Khairy, M. Design and evaluation of optical mesocaptor for the detection/recovery of $\mathrm{Au}(\mathrm{III})$ from an urban mine. Sensor Actuat. B-chem. 2014, 203, 363-374.

7. El-Safty, S.A.; Shenashen, M.A. Mercury-ion optical sensors. TrAC Trend Anal. Chem. 2012, 38, 98-115.

8. El-Safty, S.A.; Shenashen, M.A. Organic-Inorganic Mesoporous Monolithic Scaffolds and Their Functionality in Ion-Sensitive Removal of Mercury Ions. In Mercury; Source, Application and Health Impacts; NOVA Science Publishers: New York, USA, 2013; pp. 25-65. 
9. Basu, N.; Kwan, M.; Chan, H.M. Mercury but not organochlorines inhibits muscarinic cholinergic receptor binding in the cerebrum of ringed seals (Phoca hispida). J. Toxicol. Environ. Health Part A 2006, 69, 1133-1143.

10. Ros-Lis, J.V.; Marcos, M.D.; Mártinez-Mánez, R.; Rurack, K.; Soto, J. A regenerative chemodosimeter based on metal induced dye formation for the highly selective and sensitive optical determination of $\mathrm{Hg}^{2+}$ ions. Angew. Chem. Int. Ed. 2005, 44, 4405-4407.

11. Renzoni, A.; Zino, F.; Franchi, E. Mercury levels along the food chain and risk for exposed populations. Environ. Res. 1998, 77, 68-72.

12. World Health Organization (WHO). Mercury in Drinking-Water: 2005, WHO/SDE/WSH/05.08/10.

13. Zahir, F.; Rizwi, S.J.; Haq, S.K.; Khan, R.H. Low dose mercury toxicity and human health. Environ. Toxicol. Pharmacol. 2005, 20, 351-360.

14. Leopold, K.; Foulkes, M.; Worsfold, P. Methods for the determination and speciation of mercury in natural waters-A review, Anal. Chim. Acta 2010, 663, 127-138.

15. Cerutti, S.; Silva, M.F.; Gásquez, J.A.; Olsina, R.A.; Martinez, L.D. On-line preconcentration/determination of cadmium in drinking water on activated carbon using 8-hydroxyquinoline in a flow injection system coupled to an inductively coupled plasma optical emission spectrometer. Spectrochim. Acta Part B: At. Spectrosc. 2003, 58, 43-50.

16. Mahajan, R.K.; Kaur, I.; Lobana, T.S. A mercury (II) ion-selective electrode based on neutral salicylaldehyde thiosemicarbazone. Talanta 2003, 59, 101-105.

17. Puk, R.; Weber, J.H. Determination of mercury (II), monomethylmercury cation, dimethylmercury and diethylmercury by hydride generation, cryogenic trapping and atomic absorption spectrometric detection. Anal. Chim. Acta 1994, 292, 175-183.

18. Bloxham, M.J.; Hill, S.J.; Worsfold, P.J. Atomic spectrometry update advances in atomic absorption and fluorescence spectrometry and related techniques. J. Anal. At. Spectrom. 1996, 11, 511-514.

19. El-Safty, S.A.; Abdelllatef, A.; Ismeal, M.; Shahat, A. Optical Nanosphere Sensor Design based Shell-By-Shell Fabrication for Removal of Toxic Metals from Human Blood. Adv. Healthcare Mater. 2013, 2, 854-862.

20. El-Safty, S.A. Organic-inorganic hybrid mesoporous monoliths for selective discrimination and sensitive removal of toxic mercury ions. J. Mater. Sci. 2009, 44, 6764-6774.

21. Balaji, T.; El-Safty, S.A.; Matsunaga, H.; Hanaoka, T.; Muzukami, F. Optical sensors based on nanostructured cage materials for the detection of toxic metal ions. Angew. Chem. Int. Ed. 2006, 45, 7260-7266.

22. El-Safty, S.A.; Shenashen, M.A.; Khairy, M. Optical detection/collection of toxic Cd(II) ions using cubic Ia3d aluminosilica mesocage sensors. Talanta 2012, 98, 69-78.

23. Henke, K.R.; Robertson, D.; Krepps, M.K.; Atwood, D.A. Chemistry and stability of precipitates from aqueous solutions of 2,4,6-trimercaptotriazine, trisodium salt, nonahydrate (TMT-55) and mercury (II) chloride. Water Res. 2000, 34, 3005-3013

24. Chiarle, S.; Ratto, M.; Rovatti, M. Mercury removal from water by ion exchange resins adsorption. Warer Res. 2000, 34, 2971-2978 
25. Chen, K.H.; Lu, G.H.; Chang, J.B.; Mao, S.; Yu, K.H.; Cui, S.M.; Chen, J.H. Hg (II) ion detection using thermally reduced graphene oxide decorated with functionalized gold nanoparticles. Anal. Chem. 2012, 84, 4057-4062.

26. Evans, O.; McKee, G.D. Determination of mercury (II) and organomercury compounds by reversed-phase liquid chromatography with reductive electrochemical detection. Analyst 1988, 113, 243-246.

27. Mondal, S.; Wickramasinghe, R.S. Produced water treatment by nanofiltration and reverse osmosis membranes. J. Membrane Sci. 2008, 322, 162-170.

28. Li, Z.; Wei, Q.; Yuan, R.; Zhou, X.; Liu, H.; Shan, H.; Song, Q. A new room temperature ionic liquid 1-butyl-3-trimethylsilylimidazolium hexafluorophosphate as a solvent for extraction and preconcentration of mercury with determination by cold vapor atomic absorption spectrometry. Talanta 2007, 71, 68-72.

29. Aguado, J.; Arsuaga, J.M.; Arencibia, A. Aqueous heavy metals removal by adsorption on amine-functionalized mesoporous silica. J. Hazard. Mater. 2009, 163, $213-221$.

30. El-Safty, S.A; Ismael, M.; Shahat, A.; Shenashen, M.A. Mesoporous hexagonal and cubic aluminosilica adsorbents for toxic nitroanilines from water. Envir. Sci. Poll. Res. 2013, 20, 3863-3876

31. Campbell, T.; Corker, J.M.; Dent, A.J.; El-Safty, S.A.; Evans, J.; Fiddy, S.G.; Newton, M.A.; Ship, C.P.; Turin, S. Synthesis, Characterization and Chemistry of Transition metals in mesoporous silica. Stud. Surf. Sci. Catal. 2001, 132, 667-672.

32. El-Safty, S.A.; Hanaoka, T. Synthesis of monolithic nanostructured silicate family materials through the lyotropic liquid crystalline mesophases of non-ionic surfactant. Stud. Surf. Sci. Catal. 2003, 146, 173-176.

33. El-Safty, S.A.; Mizukami, F.; Hanaoka, T. Monolithic ordered silica with large cage and cylindrical structures, and hydrothermal stable frameworks. Stud. Surf. Sci. Catal. 2005, 158A, 431-438.

34. Khairy, M.; El-Safty, S.A.; Ismael, M. Mesoporous nanomagnet supercaptors for selective heme-proteins from human cells. Chem. Commun. 2012, 48, 10832-10834.

35. Khairy, M.; El-Safty, S.A. Selective encapsulation of hemoproteins from mammalian cells using mesoporous metal oxide nanoparticles. Coll. Surfaces B: Biointerfaces 2013, 111, 460-468.

36. El-Safty, S.A.; Shenashen, M.A.; Khairy, M. Trapping of biological macromolecules in the three-dimensional mesocage pore cavities of monolith adsorbents. J. Porous Mater. 2013, 20, 679-692

37. Das, S.K.; El-Safty, S.A. Development of Mesoscopically Assembled Sulfated Zirconia Nanoparticles as Promising Heterogeneous and Recyclable Biodiesel Catalysts. ChemCatChem 2013, 5, 3050-3059.

38. El-Safty, S.A. Synthesis, Characterization and Catalytic Activity of Highly Ordered Hexagonal and Cubic Composite Monoliths. J. Colloid Interface Sci. 2008, 319, 477-488.

39. Hoa, N.D.; El-Safty, S.A. Highly sensitive and selective volatile organic compound gas sensors based on mesoporous nanocomposite monoliths. Anal. Methods 2011, 3, 1948-1956.

40. Khairy, M.; El-Safty, S.A. Hemoproteins-nickel foam hybrids as effective supercapacitors. Chem. Commun. 2014, 50, 1356. 
41. El-Safty, S.A.; Mizukami, F.; Hanaoka, T. Adsorption of Aniline onto Hexagonal Mesoporous Silicate Monoliths (HOM-2). Int. J. Envir. Poll 2008, 33, 1-4, 97-112.

42. Yang, Z.L.; Niu, Z.W.; Cao, X.Y.; Yang, Z.Z.; Lu, Y.F.; Hu, Z.B.; Han, C.C. Template synthesis of uniform 1D mesostructured silica materials and their arrays in anodic alumina membranes. Angew. Chem. Int. Ed. 2003, 42, 4201-4203.

43. Ho, W.S.W.; Sirkar, K.K. Membrane Handbook; Van Nostrand Reinhold: New York, NY, USA, 1992.

44. Martin, C.R. Nanomaterials-a membrane-based synthetic approach. Science 1994, 266, 1961-1966.

45. Gong, Z.H.; Ji, G.B.; Zheng, M.B.; Chang, X.F.; Dai, W.J.; Pan, L.J.; Shi, Y.; Zheng, Y.D. Structural characterization of mesoporous silica nanofibers synthesized within porous alumina membranes. Nanoscale Res. Lett. 2009, 4, 1257-1262.

46. El-Safty, S.A.; Shahat, A.; Warkocki, W.; Ohnuma, M. Building-block-based mosaic cage silica nanotubes for molecular transport and separation. Small 2011, 7, 62-65.

47. El-Safty, S.A.; Hoa, N.D.; Shenashen, M.A.; Topical developments of nanoporous membrane filters for ultrafine noble metal nanoparticles. Eur. J. Inorg. Chem. 2012, 9, 2288-2296.

48. Anthony, Y.K.; Seth, T.T.; Sergio, M.L. Mesoporous silica composites containing multiple regions with distinct pore size and complex pore organization. J. Am. Chem. Soc. 2005, 127, 6934-6935.

49. Keilbach, A.; Moses, J.; Khn, R.; Dblinger, M.; Bein, T. Electrodeposition of copper and silver nanowires in hierarchical mesoporous silica/anodic alumina nanostructures. Chem. Mater. 2010, 22, 5430-5436.

50. El-Safty, S.A.; Shenashen, M.A. Size-selective separations of biological macromolecules on mesocylinder silica arrays. Anal. Chim. Acta 2011, 694, 151-161.

51. Sandell, E.B. Colorimetric Determination of Traces of Metals, 3th ed.; Interscience Publisher: New York, NY, USA, 1959; p. 326.

52. El-Safty, S.A.; Shenashen, M.A.; Shahat, A. Tailor-made micro-object optical sensor based on mesoporous pellets for visual monitoring and removal of toxic metal ions from aqueous media. Small 2013, 9, 2288-2296.

53. Khairy, M.; El-Safty, S.A.; Shenashen, M.A.; Elshehy, E.A. Hierarchical inorganic-organic multi-shell nanospheres for intervention and treatment of lead-contaminated blood. Nanoscale 2013, 5, 7920-7927.

54. Shenashen, M.A.; Elshehy, E.A.; El-Safty, S.A.; Khairy, M. Visual monitoring and removal of divalent copper, cadmium, and mercury ions from water by using mesoporous cubic Ia3d aluminosilica sensors. Sep. Purif. Technol. 2013, 116, 73-86.

55. Shenashen, M.A.; El-Safty, S.A.; Elshehy, E.A. Architecture of optical sensor for recognition of multiple toxic metal ions from water. J. Hazard. Mater. 2013, 260, 833-843.

56. El-Safty, S.A.; Shenashen, M.A. Optical mesosensor for capturing of Fe(III) and $\mathrm{Hg}(\mathrm{II})$ ions from water and physiological fluids. Sensor Actuat. B-chem. 2013, 183, 58-70.

57. Shenashen, M.A.; Shahat, A.; El-Safty, S.A. Ultra-trace recognition and removal of toxic chromium (VI) ions from water using visual mesocaptor. J. Hazard. Mater. 2013 244-245, $726-735$. 
58. Khairy, M.; El-Safty, S.A.; Shenashen, M.A.; Elshehy, E.A. Simultaneous detection and removal of cadmium ions from different environmental matrices. J. Life Cycle Assessment 2014, 10, 126-141.

59. Thommes, M.; Smarsly, B.; Groenewolt, M.; Ravikovitch, P.I.; Neimark, A.V. Adsorption hysteresis of nitrogen and argon in pore networks and characterization of novel micro- and mesoporous silicas. Langmuir 2006, 22, 756-764.

60. Van Der Voort, P.; Ravikovitch, P.I.; de Jong, K.P.; Benjelloun, M.; van Bavel, E.; Janssen, A.H.; Neimark, A.V.; Weckhuysen, B.M.; Vansant, E.F. A New templated ordered structure with combined micro- and mesopores and internal silica nanocapsules. J. Phys. Chem. B 2002, 106, 5873-5877.

61. Cruz-Chu, E.R.; Aksimentiev, A.; Schulten, K. Ionic current rectification through silica nanopores. J. Phys. Chem. C 2009, 113, 1850-1862.

El-Safty, S.A. Shenashen, M.A.; Ismael, M.; Khairy, M.; Awual, M.R. Mesoporous aluminosilica sensors for the visual removal and detection of $\mathrm{Pd}(\mathrm{II})$ and $\mathrm{Cu}(\mathrm{II})$ ions. Micropor. Mesopor. Mater. 2013, 166, 195-205.

(C) 2014 by the authors; licensee MDPI, Basel, Switzerland. This article is an open access article distributed under the terms and conditions of the Creative Commons Attribution license (http://creativecommons.org/licenses/by/3.0/). 